UDK 371.14+37.018.43

\title{
Methodological Support for Educators: Recurrent Professional Development Perspectives In the Aspect of Distance Learning
}

\author{
Anna V. Molokova, Nadezhda E. Bulankina \\ Novosibirsk Institute for Advanced Trainingand Professional \\ Retraining of Teachers, Novosibirsk
}

Abstract.

Introduction. The purpose of this article is to present an extended analysis of specifics of hybrid learning of a pedagogue in the aspect of novel value educational dominants in the frameworks of recurrent/ continuous education that finds itself at a unique moment that the public school system, as it is currently being constructed, simply isn't delivering on its promise of educational excellence for all children, and both future and current teachers-particularly for those in the underserved COVID-19 pandemic circumstances of totality of distance and e-learning formats.

Materials and methods. State and regional documents on the national project 'Education', and its innovation initiatives, concepts and programs of educational and methodological complexes for both primary school, and international languages for both primary and secondary schools, are under consideration in this opus for methodological and theoretical substantiation of the comprehensive model of distance and e-learning that is considered a new approach that brings an improved result and is intended to prove the prior philosophical message of this research study concerning the possibility to create entirely new architectures within the existing architecture of the current system of advanced training and professional retraining of educators. The methods of critical analysis, statistics, and classification, modeling and programming, content analysis, search and longitudinal experiment, questionnaires, interviews, linguistic testing, diagnosis and teaching/learning/forming stages are intended to improve student/teacher achievement results.

Results of the study. This research includes several stages that cover the following positive outcomes of the comprehensive model under consideration and discussion: 1) both monitoring and neutralizing regional professional deficits, 2) both creation and correction of modular additional educational programs for teachers that cover Pedagogy, Knowledge Content and Technology of distance and e-learning in the aspect of axiological approach, 3) favorable educational spaces to perform facilitation function of the tutors in full. Finally, the article presents a series of recommendations designed to encourage the teachers who can improve the learning conditions of the innovative educational context building new virtual spaces through different platforms that give grounds to serve an existing population in radically different ways, and to find ourselves at a unique moment of broad consensus with the public.

Conclusion. Based on the analysis of current philosophy and meth- 
Keywords:

\section{For citation:}

Дата поступления статьи в редакцию: 13 октября 2020 г. odology of training and retraining of educators in the aspect of their professional skills and competences, the authors of this study confidently state that the learners find themselves equipped to live in a world that no longer exists, and innovation in education merely is not for the sake of novelty but it is intended to increase student/ teacher achievement results.

pedagogue, distance learning technologies, e-learning, methodological support, upgrading, novel value educational dominants, cultural self-determination of an individual (CSD)

Molokova, A.V., Bulankina, N. E. Methodological Support for Educators: recurrent professional development perspectives in the aspect of distance learning// Pedagogical IMAGE. 2020. Vol. 14 No. 4. Pp. 648-657

DOI: $10.32343 / 2409-5052-2020-14-4-648-657$

\section{Introduction}

The problem statement of this study and the provisions of this article are seen in the definition of the specifics of dynamics of education innovations one has to deal with in the context of global transition of both the world and the national public education system to the distant and e-learning formats that need quite different personal capacities and professional competences to organize the spaces of social interaction for fruitful cooperation and collaboration with professionals $[1 ; 2 ; 4 ; 6]$. First and foremost, the crucial aspect concerns the problem of readiness of an individual to independently organize his/her educational and professional activities, i.e. to actualize the problem aspects of cultural self-determination of the individual's three main concepts/spheres (Bulankina, 2003) that a) consider the personal value development realized in the information and education environment of polylingua and polycultures (the phenomenon of multilingual information and education spaces as a value); b) manifest in the national consciousness in the aspect of the person's social and professional self-determination that reflects the language culture (the phenomenon of multilingual conceptual sphere of an individual as a value); c) reflect a willingness to use the diversity of expressive development and preservation of the national culture values for understanding the meaning of human existence and self-realization in life (the phenomenon of humanitarian self-organization in the cultural environment as a value). Thus, the appeal of the authors of this opus to the issues of acculturation of the information and education continuum in the postmodern era of alternative educational systems $[2 ; 3]$ is of special significance in the aspect of value components in the background of the accumulated layer of socio-cultural texts growing exponentially $[1 ; 2]$, and determines the research context and the purpose of this article - presentation of some positive results of approbation and introduction of some possible models of methodological support of teachers in the frameworks of regional distance education.

Scientific exposition \& introduction to the problem concern developing new socially significant and culturally oriented approach- 
es - learner-centered, axiological, systems, communicative, events, tutorial movement, etc., in the regional professional development spaces of a pedagogue. Scientists and practitioners are in search of meaningful technology to develop a personality of culture, and to improve the quality of the public education system via culture-oriented activities in the system of Pedagogy, Technology, and Knowledge Content, that are associated with a progressive function of recurrent professional education of a teacher. This function means the pedagogical support for dominant values - personality as a value, education as a value, patriotism as a value, native language as a value, i.e. morals as the highest forms of life at all levels of educational activities to gain a meaning. Due to this function, the meanings, values, and the system of value-semantic relations constitute the core of a person of culture $[1 ; 2 ; 5 ; 6]$. This methodological message as a challenge is becoming a priority for current philosophy of Russian public education, where spiritual and moral education is a basic human-forming process which allows a person to grow up, to become a professional, to enter the culture spaces, meaningfully to choose dominant values, and build models of behavior, programs and projects of present and future life.

An important role in this process belongs to the teacher, who is able to provide a dialogue interaction with a student. In accord with this approach, Pedagogy identifies and determines current subject-social conditions, optimal ways and means. As is the case, the individual becomes a professionally competent, cultured, socially responsible person when Pedagogy identifies and translates into a personal sphere these opportunities and trends of the society which open up for students the educational spaces and ways of their social self - realization, i.e. personal creativity, capacities and abilities in full $[2 ; 3 ; 5 ; 6 ; 7]$. By the same token, the gradual reorientation of the educational process from teaching technologies to a closer attention to the formation of the subject status of the individual in educational activities can help to define fundamental practice-oriented challenges in the aspect of communication culture at different stages of personal education. In this regard, the role and responsibility of a teacher is crucial for cultivating the basis of intercultural communication $[2 ; 3 ; 6 ; 7]$ within specially organized pedagogical situations based on reasonable principles. Primarily based on the psychological balance of the participants of the educational process allowing the exposition of human capital $[1 ; 6]$, and axiological potential of the individual in full $[1 ; 3 ; 4 ; 6]$.

However, it is no secret that communication culture of both teachers and students at school leaves much to be desired (public cynicism, reservations, inability to listen and hear others, difficult presentation of their principles, viewpoints in oral and written form, blurred judgments, obvious demagogy, etc), although the language and communication culture of compatriots is one of goals and results of education, that educators are responsible for. The communicative and professional discourse of a modern teacher has also become the number one problem of late. It is not for nothing that in some regions, along with creative competitions and projects, Olympiads are organized for knowledge of the native language, for knowledge of communication and general culture with elements of language testing to study functional literacy. Current Scholarship of educational trends, scientific educators and practitioners prove the need to promote the idea of a dialogue of cultures that one can talk about the selective attitude of the individual to the axiological realities of varied cultures. In turn, this attitude is most often based on the emotional sphere of the spiritual world of the individual, since emotional culture is the most important component of the spiritual content of the individual $[5 ; 6]$.

The dynamic social processes and economic transformations that continue to prevail in the Russia spaces of 2020 set new challenges for the education system as a whole, practically creating conditions for its rapid development in the near future and determining the image of the future of Russia. Nowadays, education is an intangible component of the "knowledge economy" as a new stage of social and cultural development, where "intellectual potential" becomes a source of growth in the educational segment of social life. Currently, in the new 
context of the national public school system of the Russian Federation characterized with its transition to the remote format at its crucial time of COVID-19 pandemic, it has become vitally significant for any person and, in particular, for a modern pedagogue, to show the methodological and motivational readiness to make up his/her individual educational trajectory, and to show the capacity to independently organized professional activities in the frameworks of lifelong/continuous education that needs to ensure the individual's competitiveness throughout the life in the spaces of increasing volumes of information and implementing novices, development technologies for improving creative capacities as qualitative indicators to solve problems of vital significance $[1 ; 2 ; 3 ; 6 ; 7]$. Thus, an extended analysis of specifics of hybrid teaching and learning of a pedagogue has to be given in the aspect of novel value educational dominants of public school education in the Region taking into consideration barriers to innovation in public education, with its problems and opportunities.

\section{Materials and methods of the study}

The empirical array is a corpus of the texts on public education, both in the frameworks of the restricted situations of COVID-19 pandemic that were exported into the educational organizations of the Region to minimize the deficits of the current infrastructure, to stabilize and improve the workforce that was a success this time. Consequently, some of the state institutions of professional upgrading and development of education workers in the Novosibirsk region have to be ready to provide an opportunity to receive various educational services of the methodological support in the frameworks of hybrid (face-to-face \& distance) teaching and learning, advanced training via professional training and retraining programs (no less than 16 hours), including internship programs, professional retraining (no less than 250 hours), training of highly qualified personnel (postgraduate courses), group and individual consultations, etc. (in accord with its license, state assignment and contracts with individuals and legal entities).

As is the case, the educational process at the Institute is in various formats: full-time, parttime, i.e. part-time with a variety of work schedules, the number of programs implemented using distance learning technologies and e-learning in the pre-Moodle environment is increasing (about 90 per cent of programs in accord with the academic workforce in the year of 2020). In accord with the Order of the Government of the Novosibirsk region (27.03.2020, No. 43) "On additional measures for protecting the population and territory of the Novosibirsk region from emergency situations", the Order of the Government of the Novosibirsk region (18.03.2020, No. 72-p) and some other state documents that concern the Covid-19 pandemic, crucial management decisions related to the methodological support for teachers in the region have been made in the Institute educational spaces. Due to the increased relevance of self-education and recurrent/lifelong learning, a number of questions related to self-education and self-determined process have arisen, i.e. culture self-determination/self-realization, self-organization, self-motivation, self-learning and some others that cover the capacity of manage oneself, self-control and self-management in the frameworks of the comprehensive model of culture self-determination/self -realization of a person in the poly-lingua space [1; 6]. So the concept of methodological support in the analytical survey relates to the internal and external aspects of the individualized/personalized learning process - the motivation for acquiring certain skills, the decision-making system necessary to optimize the teaching/ learning process, the ability to manage and direct it towards achieving aims related to the students/teachers' goals, needs and interests which constitute methodological activities of the educators in the situation of diagnosis of their professional deficits and help overcome their identified problems, relying on both the individual capabilities and competences, and the opportunities of the regional educational environment.

\section{Results and their discussion}

Annually the educators of the Institute, professors and specialists in methodology, did their best to provide the methodological support in the frameworks of the Tutorials. Within 
the period of pandemic restrictive measures the management of distance learning takes place in the events and learner-centered educational spaces in full $[2 ; 4 ; 6]$ :

a) Longitudinal research survey (since the 90ies of the last century) carried out distance learning technologies and e-learning as the core of the Tutorials.

b) Some of the seminars and conferences (as an example, the Annual Regional conference "Specifics of Digital School Development in the Novosibirsk region») held at the heart of the educational recurrent professional development spaces.

c) A unique system of methodology seminars organized by the Department of Information Technologies in Education as the mainstream of the development of remote competences of the Institute experts, i.e. professors, and education managers/operators.

d) These Regional Startups of the above activities carried out within the professional competences of educators and Knowledge Content of the Tutorials Teamship of the Institute as the trends of the educational spaces for a symmetrical response to the identified methodological deficiencies/deficits of schoolteachers at a unique moment of broad consensus that the public school system delivers on its promise of educational excellence for all the students.

As one can see, there is a lot of promising energy behind innovations in public education nowadays, but that energy will yield little if we don't act quickly to establish some common definitions and principles that can underpin and sustain the work ahead to consider the existing pedagogical and psychological realia in terms of methodological support for the schoolteachers after the introduction of restrictive measures and up to the present crucial moment. So, the following research methods were used to conduct this survey: the analysis of the prerequisites and current situation regarding the readiness of the system of recurrent professional education on the example of a regional Institute to meet the need of teachers to improve their skills and competences to neutralize a wide range of specific deficits; modeling of a new system of tutor support; interviewing and questioning teachers to obtain reliable information about their professional deficits, to minimize them while programming the educational spaces, to identify deficits, and to analyze the results of a survey of 583 teachers of refresher courses at the Institute in March 2020.

At the first stage this research considers the results that need further discussion and consideration of the problem of barriers to innovation in public school education and professional deficits of educators. The first trend as a deficit concerns the need to adjust the educational programs of academic subjects, courses, and teaching methods in connection with the transition to the implementation of the educational process with the predominant use of distance technologies and e-learning.

As one of the fruitful results of this longitudinal theory and practice investigation/survey is the identification of the following main barriers to innovations in public education - traditional political and structural arrangements in public school system restrict confusion for policy makers and inhibits innovation; lack of clear and common metrics; weak technology infrastructure; weak knowledge base; fragmentation and oligopoly; misaligned labor market; research divorced from problems of practice; ineffective uptake and dissemination, so on and so forth. As a second one is the development of the staff of the Institute promptly providing recommendations in all academic subjects of public general education to extend the learning in the First through Eleventh grade classrooms (GS general school - 1-11). Guidelines for content adjustment of educational programs under restrictive measures" are available on the Institute's Website that gives the opportunity to blended learning to combine the best features of traditional schooling with the advantages of online learning to deliver personalized, differentiated instruction across a group of learners

(http://www.nipkipro.ru/novosti/publikatsii/metodicheskie-rekomendatsii-po-soderzhatelnoy-korrektirovke-obrazovatelnich-programm-v-usloviyach-ogranichitelnich-mer.html electronic resource).

Planning and programming of professional development of a pedagogue carried out 
during this period with the predominant use of distance technologies and e-learning, these issues of change of Knowledge Content, Pedagogy and Technology, the methodology of presenting it to educators, were considered in detail, and as a whole. In addition, the START-UP events of the XX Congress of Education Workers of the Novosibirsk region, organized by the Institute, were held in a remote format. Instead of fourteen previously planned interactive events (planned coverage -500 teachers), two online collaborations on dominant educational values of the regional education system were held (more than 2,650 participants). The most crucial methodological issues were considered, i.e. testing the projects for methodological support of teachers in management of the educational process in remote format, and the implementation of inclusive education in the context of distance learning.

The second trend as a dominant professional deficit manifests itself objectively because of the tension of relations in the triad "Teacher-Student-Parents" due to the need to organize the educational process at home using distance technologies and e-learning. Teachers have difficulties both in application of Technology toolkits and in upgrade of Knowledge Content of educational materials that could be effectively used in the context of restrictive measures. By the same token, there is a great deficit in upgrade/promotion of innovation within the system of interaction with the participants of the educational process. Hundreds of emotional appeals were received within the first two weeks in the frameworks of the new educational format on the hotline, organized by the Regional Headquarters for supporting distance learning of schoolchildren. The response of the Institute, the Experts Teamship (ET), on the first days of the introduction of restrictive measures, becomes an Expert Consultative Center for the teachers of the Region on methodological issues that concern the problems of effective communication at a unique moment of total self-isolation which were solved in no time.

At the second stage of the study the correlation of Knowledge Content of planning and programming of the professional development and retraining of teachers in the Novosibirsk region, who, due to COVID-19 pandemic, started/continued to improve additional professional programs, preferably, with distance technologies and e-learning modules that need relevant electronic resources. As an example of the model element is the inclusion of the module on acquaintance with the popular distance education platform "Yaklass/Iclass" into all our programs. Shortly, 25 math teachers, 25 primary school teachers, 84 chemistry and biology teachers, 31 geography teachers, 27 physics and astronomy teachers, 33 information technology teachers, and 29 Russian language and literature teachers were retrained to promote the platform's capabilities in educational organizations in the Region. Additional professional development programs "Modern online services for the digital educational environment", implemented by the Department of information technologies in education, and "designing the educational process in the school's IOS", developed at the Department of Primary Education, focused teachers on the direct implementation of the acquired competencies in practice.

The next trend concerns the contribution to the process of methodological support that was initiated the discussion on the topical issues of the content and organization of the educational process with the dominant usage of distance technologies and e-learning in the Regional network of communities of teachers of different disciplines. It is significant that methodological coordination of the activities of two-thirds of them is carried out by the Institute Experts. Thus, primary school teachers actively discussed the organization of evaluation activities of teachers/ students in the context of distance learning. Almost five hundred teachers shared their experience, asked questions, and presented their achievements, methodological ideas to each other (TeachMeet Technology). The operator-coordinator-tutor-expert initiated problem forums on a relevant topic, consulted teachers and gave relevant information of how to overcome the problems of remote education of schoolchildren.

At the third stage the next professional deficit discovered relates to the need of teachers for external expert assessment of their efforts made to solve the problem, with the need to ob- 
tain reliable information about the broad context of the changes that take place. Operational expertise and scientific-methodical analysis of the situation, as well as reasonable proposals that would improve the quality of public school education and continuous professional education of teachers, educators/experts of the Institute initiated the online conferences, webinars on different problems, and methodical log at the Federal level, including scientific-methodical journal "Siberian teacher". As is the case, the target publications for programming and modeling the systems work are published by the authors $[4 ; 5 ; 6]$.

By the same token, the criteria for evaluating all regional professional skill competitions organized remotely in 2020 have changed. Among the criteria for evaluating the results is the quality of implementation of the basic educational programs at different levels of public school education in the conditions of distance technologies and e-learning. On the one hand, an additional criterion is a guide for teachers on the priorities of the new reality. On the other, it allows experts to focus on new relevant practices; identifying winners with this criteria, to ensure the dissemination of the best pedagogical practices within the finals of pedagogical conferences based on the results of regional competitions.

One of the most difficult professional deficits, the fourth one, is the need to master new IT tools, and to use them adequately to solve educational problems in teaching practice, and this deficit has become a challenge to the existing algorithms for implementing distance learning by specialists of the Regional Institute. At the request of teachers in the course of professional development, all departments of the Institute use not only the remote platform for distance education Moodle, which has been working at the Institute since 2010, but also Zoom, BBB and others. As part of the courses, students/teachers develop competencies in using these platforms and gain experience in using them in their professional activities. For example, in June 2020, about 400 people were trained using the BBB platform in an interactive online mode as part of the PC courses for management employees. The ZOOM platform is used by speech therapists to improve the skills of primary school teachers, preschool education workers, and others. The experience of using Zoom, BBB, and Moodle, as well as the practice of creating and using educational electronic products for children and parents using WhatsApp and other messengers, using YouTube, is under consideration at methodological seminars dedicated to distance learning for schoolchildren.

At the fourth stage of this study special attention is drawn to the fifth professional deficit determined by the headmasters/managers of educational organizations. Experts of the Institute need to provide methodological support for the leadership teams of educational organizations in terms of improving the effectiveness of distance learning for schoolchildren, preparing and making adequate management decisions shortly. To minimize this deficit, the resource of the Department of education management was updated, and served as the operator of the Regional project "Regional resource centers for education development". The methodological support consisted of the development and implementation of professional retraining programs on the topic "Lesson research as a way to improve the quality of education (course support for teachers)" on the remote platform "Directory Academy". Thus, during the retraining programs teachers took part in a 9-day Online Forum on "How School can switch to distance education without stress" of four modules that include legal advice and methodological support for managers and teachers. Further on, topical events in educational organizations of Novosibirsk and the Novosibirsk region were held by managers, and dedicated to the organization of the educational process in the context of distance learning.

\section{Conclusion}

Having entered the global world of education, Russia has opened novel opportunities for the development of varied spheres of socio-economic and education activities. Making the most of regional opportunities for teachers to comprehend factual information in order to build Knowledge Content that creates a desire to be lifelong learners is essential to our educational landscape. Current public school system is considered a sociocultural phenomenon 
and a valuable segment for preserving and enhancing culture traditions, dominant values, as well as systems training experts on increase of both economic and intellectual potential of the country and the people that are to be cultivated and respected. These issues are still under scientific discussion, but the intensity of export of fruitful humanitarian practice into the real educational processes is insufficient.

Consequently, the practical significance of this study is seen in the professional development education planned a) to minimize professional deficits and improve the qualification of teachers of all the subjects on organizational and methodological issues of distance technologies and e-learning; b) to upgrade the infrastructure of arrangements in education restrict innovation that include the development of distance courses in LMS Moodle, practice-oriented seminars on the use of public social services as well as further methodological support for the activities of regional network pedagogical communities within the professional project "Novosibirsk Destination" educational landscape; c) to modernize and test professional educational programs and topicality of modules; d) to organize interactive events and dissemination of humanitarian practices as the most important design elements of the value model of tutor support for students/teachers in the information and educational spaces at the institutional, municipal and regional levels created in the course of this research that is in need of further clarification and testing.

Meanwhile, innovation in the framework of this value model of culture self-realization of a pedagogue is not merely about a final product, but also about the conditions and factors that allow innovators to see a problem in a new light, create potential solutions, refine their approaches, and ultimately bring fresh and effective ideas, products, processes, and platforms that are captured and disseminated broadly, and applied towards thinking through the next crucial challenges of the poly-cultures world and global education.

\section{The final manuscript of this opus HAS been thoroughly read and approved by two of the authors. N. Bulankina, A. Molokova.}

\section{References}

1. Bondarevskaya E. V. (2002). Unified educational space of the North Caucasus as an environment for educating a person of culture and morality / Materials of the All-Russian Conference "Integration of Cultures in Essence-Created Education". Makhachkala: DSU, Pp. 5-10. (in Russ.).

2. Bulankina N. E., Malakhova, N. N. (2019). Some problems of improving the abilities of students in accordance with the peculiarities of the interpretation of recurrent education // KANT. No. 2 (25). Pp. 32-37. (in Russ.).

3. Kartashova V. N. (2020). Historical and Cultural Heritage of the Region as a Substantive Basis for the Implementation of the Regional Approach in German Language Classes // Sibirskii Uchitel. No. 4 (131). Pp. 109-114. (In Russ.).

4. Molokova A. V. (2016). Modern Regulatory Requirements for ICT-competences of Teachers and their Feasibility // Pedagogical Review. No. 1 (11). Pp. 64-68 (In Russ.).

5. Philological education in the context of the digital environment (2019) / Collection of scientific articles on the results of the all-Russia scientific and practical conference of the Year. Russian Academy of Education, Moscow, May 30, 2018. Galaktionova T. G., Kazakova E. I., Pugach V. E, and others. Saint Petersburg: LEMA Publishing House. 2019. Pp. 31-34. (In Russ.).

6. Lopatukhina T., Egorova E., Bulankina N., Mishutina. O. (2020). Personalized education: origins, characteristics and technology of use. [Electronic resource] // EduLearn, 2020, WoS, Valencia (Spain) 2020. 6-8 July Pp. 899-904 (in Engl.). https://apps.webofknowledge.com/full_record.do?product=WOS\&search_mode=GeneralSearch\&qid=7\&SID=- 
F3uw8faqG5F6v5Fzw6I\&page $=24 \&$ doc $=1155$

https://apps.webofknowledge.com/ full_record.do?product $=$ WOS \&search_mode $=$ GeneralSearch\&qid=7\&SID $=$ F3uw8faqG5F6v5Fzw6I\&page $=24 \& \mathrm{doc}=1156$ (mode of access: 04.08.2020).

7. Yao Wel. (2020). Implementation of the 'Flipped Class' Model in Vocal Education as one of the Directions of Reforming Higher Vocal Education in China // KANT, 2020. No. 3 (36). Pp. 418-428 (In Russ.). 
Молокова

Анна Викторовна

доктор педагогических наук, профессор, проректор

ORCID https://orcid.org/

0000-0002-1879-2937

Новосибирский институт повышения квалификации и переподготовки работников образования

Россия, 630007, г. Новосибирск, Красныий проспект, 2

тел.: +7 (383) 2237484

e-mail:amolokova@mail.ru

\section{Буланкина}

\section{Надежда Ефимовна}

доктор философских

и педагогических наук,

доиент,

заведуюший кафедрой иноязычного образования, профессор

ORCID https://orcid.org/

0000-0002-4291-6354

Новосибирский институт повышения квалификации и переподготовки работников образования

Россия, 630007, г. Новосибирск, Красныий проспект, 2

тел.: +7(383)2236667

e-mail:nebn@yandex.ru

\section{Anna V. Molokova}

Doctor of Sciences (Phd. in Pedagogy), Professor, Vice-Rector

ORCID https://orcid.org/

0000-0002-1879-2937

Novosibirsk Institute for Advanced Training and Professional Retraining of Teachers

2 Krasny Pr., Novosibirsk, Russia, 630007

tel.: +7 (383) 2237484

e-mail:amolokova@mail.ru

\section{Nadezhda E. Bulankina}

Doctor of Sciences

(Phd. in Philosophy \& Pedagogy), Associate Professor, Head of the Department of International Language Education, Professor

ORCID https://orcid.org/

0000-0002-4291-6354

Novosibirsk Institute for Advanced Training and Professional Retraining of Teachers

2 Krasny Pr., Novosibirsk, Russia, 630007

tel.: +7(383)2236667

e-mail:nebn@yandex.ru 